\title{
BUSINESS PROCESSES MANAGEMENT IMPLEMENTATION IN HEALTH SECTOR
}

\author{
López Juan D., Moreno S, Moreno L., Anzola D., López Francisco., Vilardy A., \\ Osorio R., Salinas M., Yepes D. \\ ${ }^{1}$ Chief Executive Officer, Lv Consultores, Bogotá, Colombia \\ ${ }^{2}$ Teaching researcher, ECCI University, Bogotá, Colombia \\ ${ }^{3}$ Executive Director, Lumon, Bogotá, Colombia \\ ${ }^{4}$ Software Architect, Lumon, Bogotá, Colombia \\ ${ }^{5}$ Technical Advisor, Lv Consultores, Tuluá, Colombia \\ ${ }^{6}$ Academic Advisor, Uniminuto, Bogotá, Colombia \\ ${ }^{7}$ Technical Advisor, Innova Ip, Bogotá, Colombia \\ ${ }^{8}$ Teaching researcher, ECCI University, Bogotá, Colombia \\ ${ }^{9}$ Executive Director, Innova\&Ip, Bogotá, Colombia
}

\begin{abstract}
:
Today the world is in a continuous change, where the organizations have to face the transformation and adapt to the demands. It is said that many companies need to improve and revise their processes to maintain their competitive advantages in an environment of continuous uncertainty. This is an original article where a "BPM" is implemented in the health sector that allows an organization to improve and review its critical business processes, a project that was carried out in "Rubén Cruz Vélez. Hospital" in the city of Tuluá, Colombia, where the implementation of the emergency process was carried out, with the purpose of improving the quality of processes in the health sector, an important indicator that seeks the user to be the protagonist in health security systems, to find the synergy between the Information technologies in health organizations.
\end{abstract}

\section{KEY-WORDS:}

Business Processes - Quality improvement - Emergency - Hospital Administration.

\section{INTRODUCTION}

BPM technology has become an important tool to support complex cases to coordinate in improving the performance of business processes [1].

Today's businesses must not only meet the threats of global competition; However, they also have to do so while respecting government, industry, regulatory requirements and internal standards. Meeting these challenges requires the implementation of business processes that are efficient and adapted to the needs of the industry and to the market segments that the organization serves globally [2].

BPM is a fairly new concept in management that promises many benefits to organizations; [3] However, in several ways there has been a system looking for an integral management during the last 10-15 years [4]. It is a structured method of understanding, documenting, modeling, analyzing, simulating, executing and continuously changing end-to-end business processes and all relevant resources in relation to an organization's ability to add value to the business. It is the 
current term used to encapsulate a process-oriented approach to achieve the operational efficiency of the company. [5] Organizations are increasingly recognizing the need for greater process orientation and require appropriate integrated frameworks, which will help to achieve and evaluate their BPM initiative [6].

On the other hand, health care organizations are facing increasing complexity of care, diminishing resources, and increased regulatory oversight. Suppliers are trying to improve quality and efficiency by trying to lower costs in an effort to maximize "value" [7]. A major discipline in dealing with this issue is business process modeling. The key elements of the discipline of business process modeling are as follows:

Optimize the performance of end-to-end business processes that span functions as well as processes, which could be extended beyond the company to include partners, suppliers and customers.

Keep the business process model synchronized with the execution of the process.

Train process users and analysts to manipulate a business process model where process instances can be modified.

Allow rapid iteration of processes and underlying systems for process improvement and continuous optimization [8].

With the mentioned arguments, the study, which was carried out with BPM, as a prominent current trend in management for organizational change, in the "Ruben Cruz Vélez Hospital" in order to examine its effectiveness in the aforementioned organization.

Thus, an exercise is carried out in the implementation of a BPM - URGENCIAS in the hospital "RUBEN CRUZ VELEZ" which is one of the main health centers of reference, which is located in the department of Valle del Cauca, specifically in the city of Tulua of Colombia, which has 19 health centers. It should be noted that this project is financed by the Ministry of ICT of Colombia, by the call 705 of Colciencias; Project that is led by the ECCI University, The Innova IP Company with the consulting group LVConsultores.

\section{MATERial AND MeThOD}

This study was developed in Rubén Cruz Vélez hospital in the city of Tuluá - Colombia. The scope of the Project includes four preferable processes that are selected by the technical committee of the hospital and the research group and the objectives of the defined and determined action plan of the project.

Project seeks to improve the processes carried out in four phases. The first phase is to identify the current situation and the priority processes. To carry out the business processes of redesigning several of the best practices that can be distinguished [9]

Given this, the processes were organized through the following four steps:

1. Conducting interviews with experts from senior hospital managers.

2. Teaching the concepts of the process.

3. Conducting meetings for the processes selected.

4. Organizing process teams. 
As mentioned in step 3, the meetings were important in order to select the list of high priority processes under the supervision of the hospital manager and scientific director.

Business process modeling has gained wide acceptance as a valuable design and management technique for different purposes [10].

The second phase is the modeling of the selected processes, which comprises four steps, which are as follows:

- Provide an overview of the concepts of processes and their modeling techniques.

- Conducting modeling and documentation meetings of the experimental processes.

- Identification of development indicators.

The third phase is aimed at identifying problems, summarizing and improving the selected processes. This phase consists of two steps that are mentioned below:

- Address doubts and suggestions, finish process forms and flow diagrams.

- Organizing meetings on how to improve test processes and change the workflow.

This stage comprises and complements the "analyze and design a process" forms and the identification of opportunities for improvement and relevant actions.

Finally, the fourth phase, which aims to be a synthesis, development and finalization of the documentation of the selected processes. This phase consists of three steps:

1. The finalization of the proposals of the processes to be improved.

2. The development of ID for the selected processes

3. Process development including document guide and manuals, procedures for updating processes, registration and analysis of information on the procedure applied.

\section{RESULTS}

\subsection{Case Study in Business Process Management in Hospital Rubén Cruz Vélez}

An important first step in developing a BPM in health is to improve a problem of inefficiency or lack of information or communication. In order to execute an appropriate process, the situation must be carefully evaluated: this is known as the construction of meaning, for this, 4 very important processes were defined from all processes handled by the hospital:

\section{Emergency services}

2. External Consultation

3. Reference and Counter-Relief

4. Collection and recovery.

Where in the case of this study everything is analyzed and developed from the emergency process, and from there the others start.

\subsection{The Architecture}

The system was developed using the MVC (Models / Vista / Contorlador) pattern as shown in figure 1: 


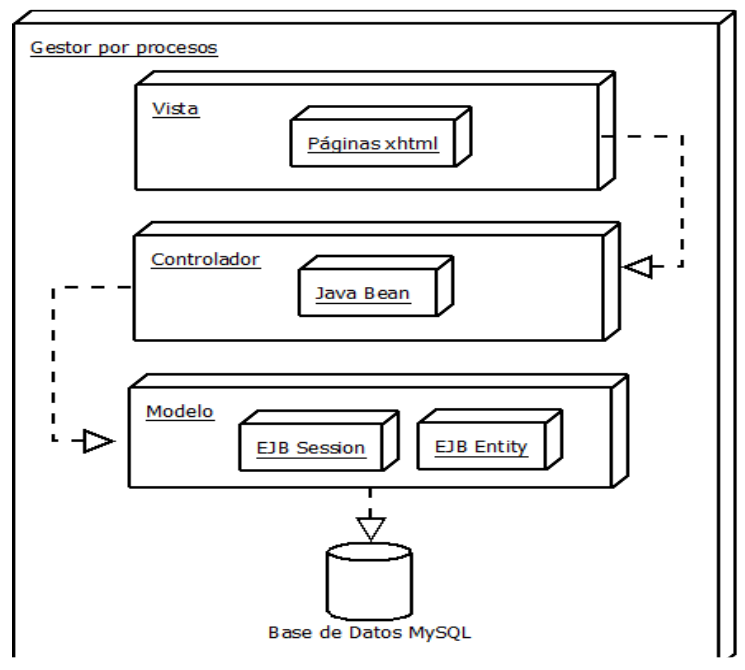

Figure 1. Architecture

Under the Java programming language, framewoks were used for the development of the project, this set of tools and libraries are GPL license, therefore no licenses are required for the development, installation and use of the system.

- Application Server: Glassfish

- Database: MySql

- Framewoks used: JSF 2.2, primefaces5.3

- ORM: EclipseLink (JPA 2.1)

\subsection{Requirements}

For the survey of requirements the SCRUM methodology which allows to work collaboratively with the interested parties and to use documentation artifacts not as complex as the stories of users and prototypes was used. This is an agile methodology that perfectly matches the dynamics of work of the team. The initial requirements were defined and the user histories were realized:

- User History

- Documentation of the Hospital's quality management system.

- BPM process diagram

\subsection{BPM Process Manager}

For the development concepts were used that were found in a BPMS system as the process tray, which allows visualizing the tasks that the user has pending to execute. 
International Journal of Managing Public Sector Information and Communication Technologies (IJMPICT)

Vol. 7, No. 4, December 2016

Ruben Cruz Vélez...

DIGITE SU USUARIO:

-

DIGITE SU CONTRASEÑA:

\section{ACCEDER OLVIDO SU CONTRASEÑ̃}

Figure 2. Registration System

The first thing to do is to log in the system, if it is registered the process tray is the first interface, figure 2, which displays the user where the tasks are enabled according to the role or profile that the user has, a task can be executed by a profile. This is configured in the database where the TAREA table has relation to the Profile as shown in figure 3.

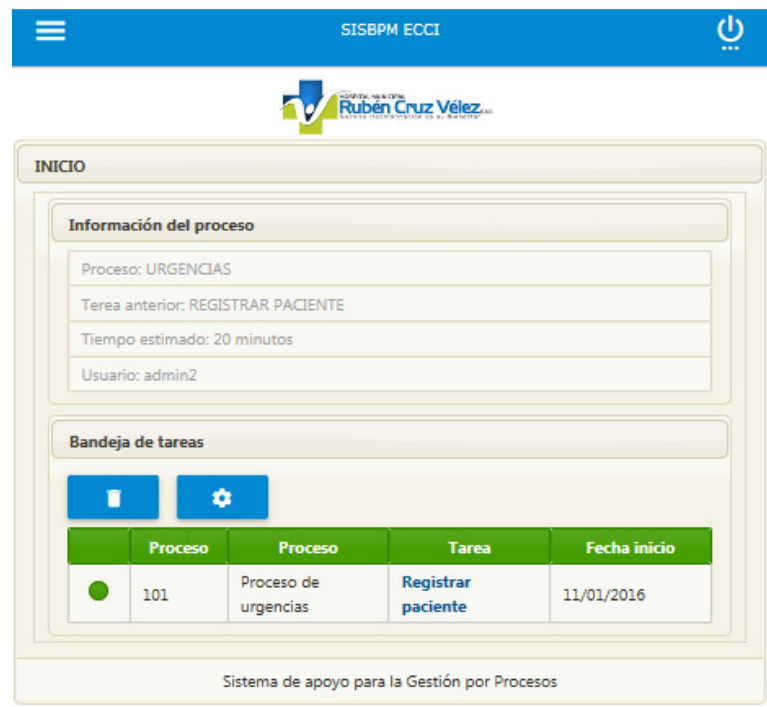

Figure 3. Relationship to Profile

Any process is parameterizable by database, for which it is necessary to define the task that initializes the process (Task 0), for the case of the emergency process is "Patients Registration", as shown in Figure 4. 
International Journal of Managing Public Sector Information and Communication Technologies (IJMPICT) Vol. 7, No. 4, December 2016

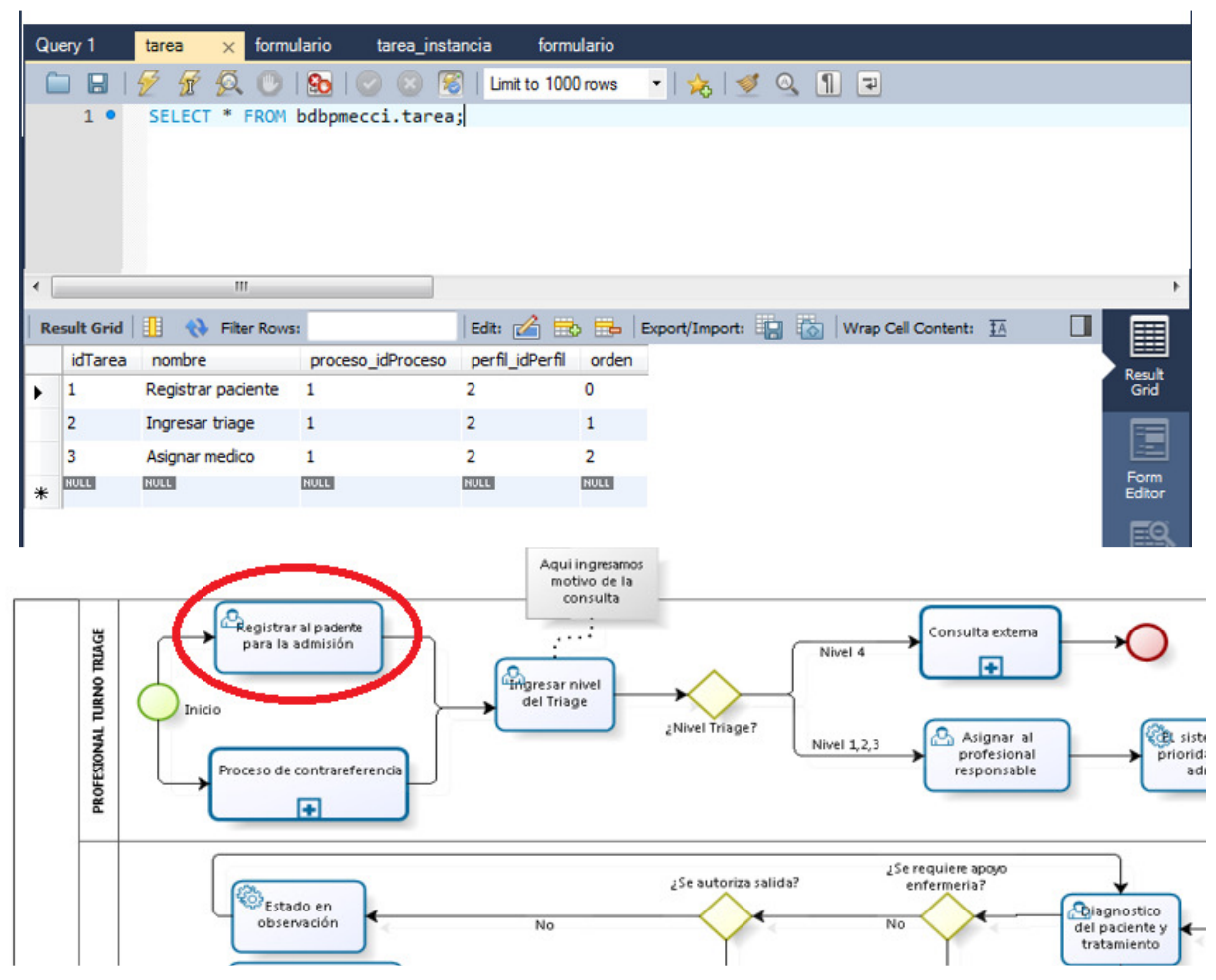

Figure 4. Patients Registration

With the "Start Process" button, the system queries the processes and tasks available for the logged profile with zero order (0), see figure 5.

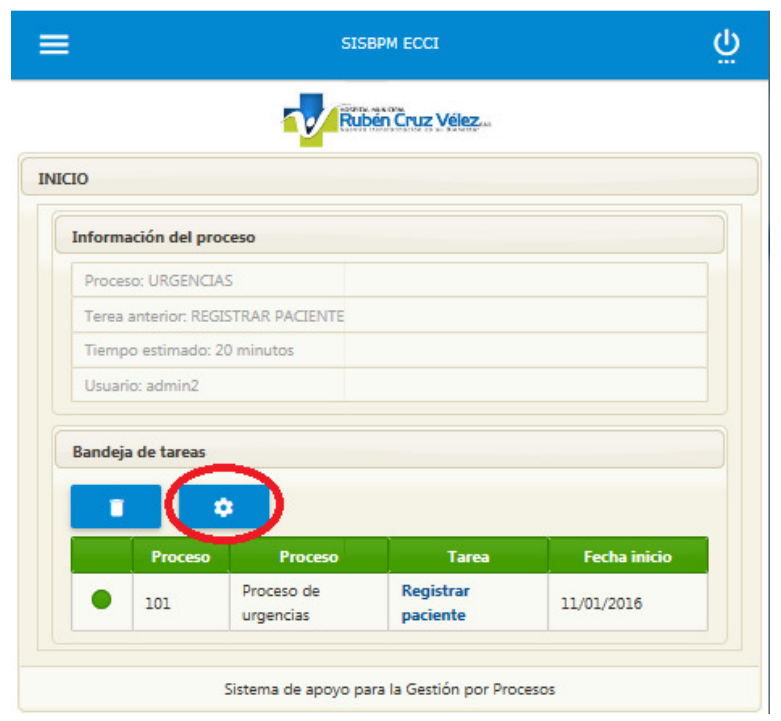

Figure 5. Processes and Tasks Available for the Profile Logged

A list is shown in Figure 6 where the user allows initializing the process where the first task for the user in session will be "Register Patient". 
International Journal of Managing Public Sector Information and Communication Technologies (IJMPICT)

Vol. 7, No. 4, December 2016

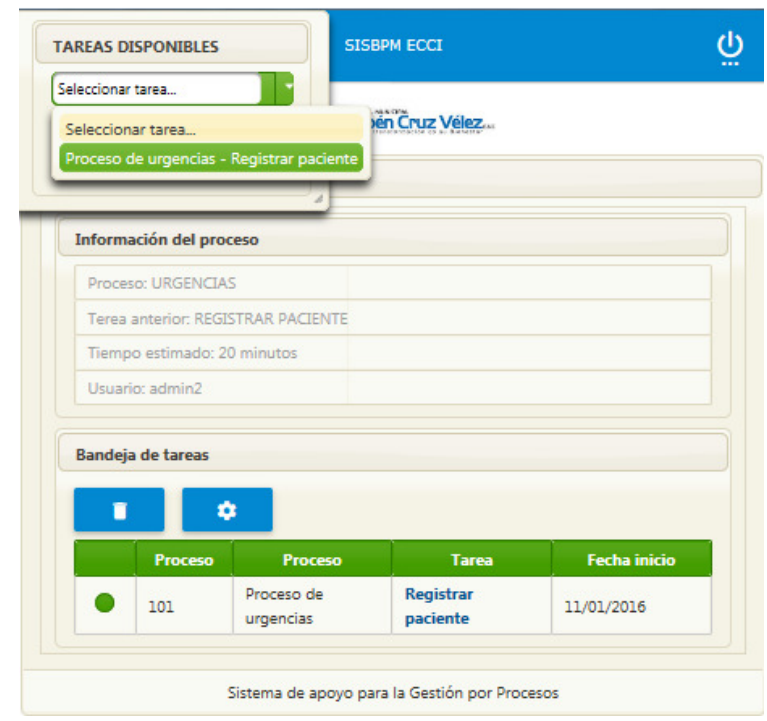

Figure 6. Patients Registration

Already activated in your process tray you can click on the task and the system displays a form to register the tasks. See Figure

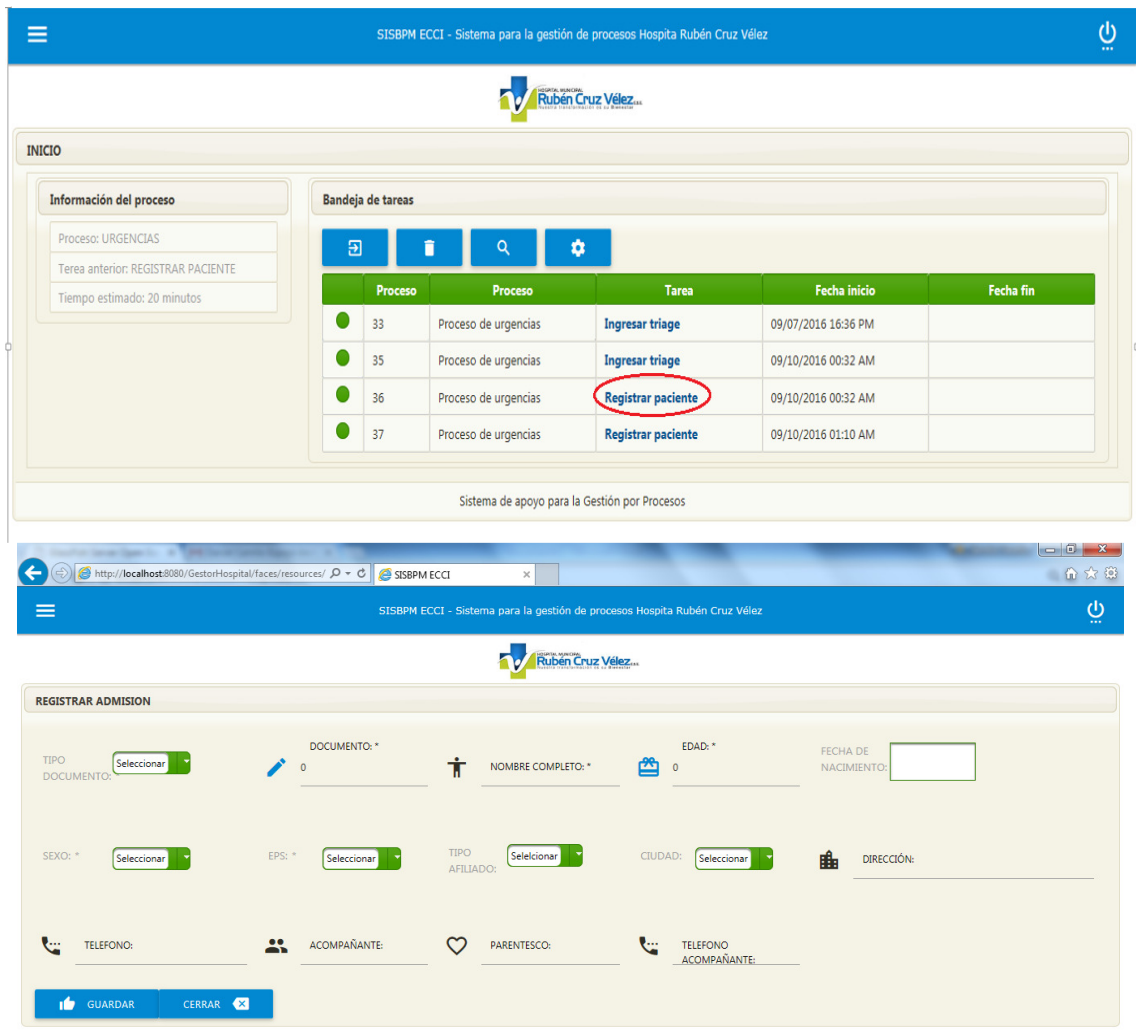

Figure 7. Tasks Registration 
Following the normal flow of events, the tasks have a sequence in our process therefore in the database they are numbered with the field "order" and as explained in the previous section the task zero (0) initializes the process. The task One (1) allows to enter the level of Triage and task two (2) allows to assign to the professional responsible, the decisions are programmed in the forms and remain as process variables in the TASK_INSTANCIA table in this case when entering the task "Login Triage" the decision will be found in the" Level triage " list of the following form, see figure 8:

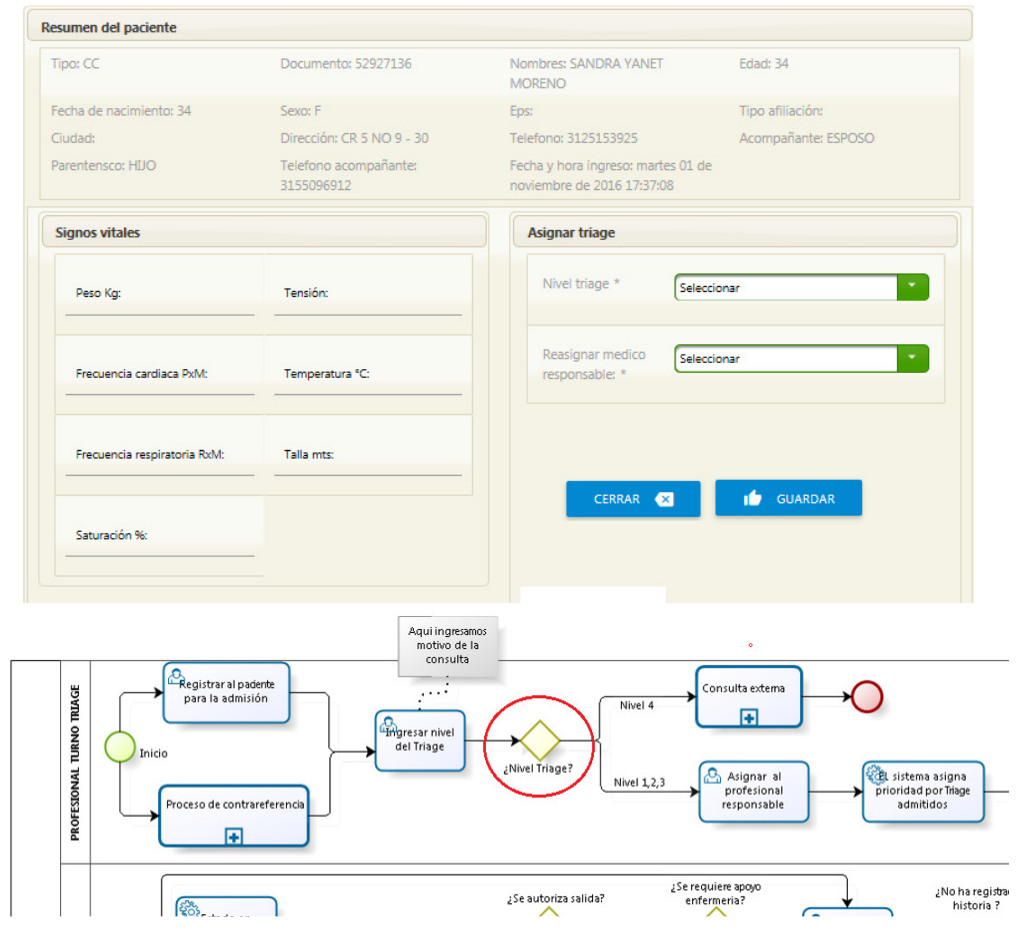

Figure 8. Triage Levels

In this way, the programming paradigm is changed when the development of an information system based on CRUD (Create / Read / Update / Delete) operations is not sought, but in processes, this approach has great benefits compared to traditional systems. Which allows strategic alignment with the entity and its quality management system.

On the other hand, knowledge management is made easier since the same system guides the user in the process and not the other way around, so the user implicitly follows the process.

The development time of new processes is inferior due to the BPM philosophy used, the development consists in the construction of new xhtml forms that are parameterized in the table FORMS as new resources, for which in a future version of the process manager a module can be added where the construction of forms is done through a graphical interface that can be used by the user, which makes the proposal scalable and economically more attractive.

Another advantage is that it allows us to go into detail in the processes both at the time of diagramming and implementation, which allows us to identify improvements in it, for example when we detect that we are doing very manual tasks and we can automate them. 
The system is scalable so that it can access other external information sources through a layer of services, which makes it integrated and interoperable with other information systems present the organizations. For the practical case, some clinical history services will be consumed in HL7, which are still pending definition.

And the most important thing is that in the health business the integration of a system based on BPM architectures allows to measure response times, generate alerts when required and with this greatly improve the perception of hospitals and health networks in Colombia.

\section{Conclusion}

The proposed system allows a systemic view of all processes of the entity that improves its direction as it becomes a strategic tool, facilitates and encourages measurement, evaluation and control of processes identifying critical points and solutions that translate into continuous improvement.

A health reform is important so that health organizations can focus on streamlining their processes in order to provide high quality care and reduce costs.

BPM gains importance in our global industry [11] [12] as well as in the organization of health services. In this project, BPM was carried out at the Rubén Cruz Vélez Hospital in order to examine a result of the establishment of a BMP in the emergency process, awaiting significant improvements in the selected process, and generating a space for more research, hoping that the current project will lead to more research in this area, especially in Colombia.

\section{ACKNOWLEDGEMENTS}

Mainly Colciencias Doctor Emiro Tovar and Ministry of ICT Doctor Nestor Fajardo, with its valuable contribution to the research project to fruition towards the Latin American Research, a special thanks to the Mayor of the City of Tulua, the Lord Mayor Gustavo Velez and Secretary TIC Alexander Andrade, believing the project to be linked in the city of Tulua, and finally thank the staff of the Hospital Ruben Cruz Vélez, Doctor Devia, Montano, Jose a and especially to Dr. Julio Cesar Toro, for giving us the doors Ruben Cruz Hospital open Velez beneficiary Project funded research by Francisco Jose de Caldas COLCIENCIAS Fund, Ministry of information Technology and communications Mintic, ECCI University, Innova \& Ip LTDA - Project No. 535-2015

\section{REFERENCES:}

[1] Weber B, Mutschler B, Reichert M. Investigating the effort of using business process management technology: Results from a controlled experiment. J Sci Com Prog. 2010;75:292-310.

[2] Colina JB, Cantara M, M Kerremans, Plummer DC. Cuadrante Mágico de suites de gestión de procesos de negocio. Gartner Res. 2009; 15 : 164-485.

[3] Hill JB, Cantara M, Kerremans M, Plummer DC. Magic quadrant for business process management suites. Gartner Res. 2009; 15:164-485.

[4] Alibabaei A, Aghdasi M, Zarei B, Stewart G. The role of culture in business process management initiatives. Aust J Basic Appl Sci. 2010;4:2143-54.

[5] De Bruin, Rosemann TM. Application of a holistic model for determining BPM maturity. In: Akoka J, Comyn-Wattiau I, Favier M, editors. Proceedings of the 3rd Pre-ICIS Workshop on Process Management and Information Systems. Washington DC, USA: BPTrends February; 2005.

[6] Chong S. Business process management for SMEs: An exploratory study of implementation factors for the Australian wine industry. J Inf Syst Small Bus.2007;1:41-58. 
International Journal of Managing Public Sector Information and Communication Technologies (IJMPICT)

Vol. 7, No. 4, December 2016

[7] De Bruin T, Rosemann M. ECIS 2005 Proceedings of the Thirteenth European Conference on Information Systems. Germany, Regensburg: 2005. May 26-28, Towards a business process management maturity model.

[8] Fink K, Grimm D. The Use of Business Process Management during the Implementation of Electronic Records Management Systems. [Last accessed on 2016 May 12]. Available from:http://www.ibis.in.tum.de/mkwi08/06_eGovernment/01_Fink.pdf

[9] Reijers HA, Mansar SL. Best practices in business process redesign: an overview and qualitative evaluation of successful redesign heuristics. Omega. 2005;33:283-306.

[10] Bandara W, Gable G-G, Rosemann M. Factors and measures of business process modelling: Model building through a multiple case study. Eur J Inf Syst.2005;14:347-60.

[11] Houy C, Fettke P, Loos P. Empirical research in business process management-Analysis of an emerging field of research. Bus Proc Manag J. 2010;16:619-61.

[12] Nancy Yaneth Gelvez García, Danilo Alfonso López Sarmiento, Jhon Francined Herrera Cubides. Handoff process simulation by network simulator 2 in mobile telematic networks with IPv6. 2014Vol $9 \mathrm{~N} 17$

\section{Author}

Engineer Juan Diego Lopez Vargas.

Telecommunications Engineer, Specialist Magister and doctoral student in Integration of IT in Organizations of the Polytechnic University of Valencia Spain. He is currently CEO and director of the Company LV Consultants SAS, was to held in administrative office and teaching in different institutions of higher education in Colombia, which takes about 10 years of experience in the structuring and execution of $\mathrm{R}+\mathrm{D}+\mathrm{i}$.

Sandra Moreno Engineer, Systems Engineer, with over 10 years experience in the IT sector.

Luis Gabriel Moreno Engineer, Systems Engineer, MBA, and Ph.D. candidate in Computer Science. Currently legal representative of the company Lumon S.A.S, takes about 8 years experience in the IT sector in Colombia.

Anzola Diego engineer, Systems Engineer and Master in Computer Science, Expert in software architecture, with more than 8 years of experience in the IT sector.

Francisco Javier Lopez Engineer, Systems Engineer, a specialist in software engineering with over 20 years experience in the IT sector.

Lic. Martha Salina. License in Education, Candidate Doctor of Education, more than 20 years of experience in education. Currently Vice Chancellor Academic Uniminuto headquarters of Cundinamarca.

Aldo Vilardy Engineer, Systems Engineer, you project structuring expert with experience of 5 years in sectPr IT.

Engineer Roberto Osorio. Engineer Computer Systems, with 20 years of experience in the ICT sector

Engineer David Yepes. Telecommunications Engineer, Currently legal representative of the company Innova\&Ip LTDA S.A.S, takes about 10 years experience in the IT sector in Colombia. 